\title{
M-QUASI-HYPONORMAL COMPOSITION OPERATORS
}

\author{
PUSHPA R. SURI and N. SINGH \\ Department of Mathematics \\ Kurukshetra University \\ Kurukshetra - 132119 , India \\ (Received November 12, 1985)
}

ABSTRACT. A necessary and sufficient condition is obtained for $M$-quasi-hyponormal composition operators. It has also been proved that the class of M-quasi-hyponorma1 composition operators coincides with the class of M-paranormal composition operators. Existence of $M$-hyponormal composition operators which are not hyponormal; and $M$-quasihyponormal composition operators which are not $M$-hyponormal and quasi-hyponormal are also shown.

KEY WORDS AND PHRASES. M-hyponormal, M-quasi-hyponormal, M-paranormal, normal composition operators.

1980 AMS SUBJECT CLASSIFICATION CODE. 47

\section{PRELIMINARIES.}

Let $(X, S, m)$ be a sigma-finite measure space and $T$ a measurable transformation from $X$ into itself (that is one $\mathrm{mT}^{-1}(E)=0$ whenever $\mathrm{m}(E)=0$ for $E \varepsilon S$ ). Then the equation $C_{T} f=$ fo $T$ for every $f$ in $L^{2}(m)$ defines a linear transformation. If $\mathrm{C}_{\mathrm{T}}$ is bounded with range in $\mathrm{L}^{2}(\mathrm{~m})$, then it is called composition operator. If $\mathrm{X}=\mathrm{N}$ the set of all non-zero positive integers and $m$ is counting measure on the family of all subsets of $N$, then $L^{2}(m)=\ell^{2}$ (the Hilbert space of all square summable sequences).

Let $\mathrm{f}_{0}=\frac{\mathrm{dm}^{-1}}{\mathrm{dm}}$ be the Radon-Nikodym derivative of the measure $\mathrm{mT}^{-1}$ with respect to the measure $\mathrm{m}$,

$$
\frac{\mathrm{dm}(\mathrm{ToT})^{-1}}{\mathrm{dmT}^{-1}}=\mathrm{g}_{\mathrm{o}^{\prime}} \quad \frac{\mathrm{dm}(\mathrm{ToT})^{-1}}{\mathrm{dm}}=\mathrm{h}_{\mathrm{o}}
$$

Then $h_{0}=f_{0} \cdot g_{0}$

Let $\mathrm{B}(\mathrm{H})$ denote the Banach algebra of all bounded linear operators on the Hilbert space $H$. An operator $T E B(H)$ is called M-quasi-hypornormal if there exists $M>0$ such that

$$
M^{2} T^{*} T^{2}-\left(T^{*} T\right)^{2} \geqq 0
$$


or equivalently $\left\|\mathrm{T}^{*} \mathrm{Tx}\right\| \leqq M\left\|\mathrm{~T}^{2} \mathrm{x}\right\|$ for all $\mathrm{x}$ in $\mathrm{H}[1] . \mathrm{T}$ is said to be $M$-paranormal [2] if for all unit vectors $x$ in $H$

$$
\|\mathrm{T} x\|^{2} \leqq M\left\|T^{2} \mathrm{x}\right\| \text {. }
$$

$T$ is said to be M-hyponormal [2] if

$$
|| T^{*}|| \leqq M \mid T x \| \text { for all } x \text { in } H \text {. }
$$

The purpose of this paper is to generalize the results on quasi-hyponormal composition operators in [3] for M-quasi-hyponormal composition operators.

2. M-QUASI-HYPONORMAL COMPOSITION OPERATORS.

In this section we obtain a necessary and sufficient condition for M-quasihyponormal composition operators and then show that the class of M-quasi-hyponormal composition operators on $\ell^{2}$ coincides with the class of M-paranormal composition operators. We also show the existence of M-hyponormal composition operators which are not hyponormal, and M-quasi-hyponormal composition operators which are not M-hyponormal and quasi-hyponormal.

THEOREM 2.1. Let $C_{T} \in B\left(L^{2}\right)$. Then $C_{T}$ is M-quasi-hyponormal if and only if $f_{0}^{2} \leqq M^{2} h_{0}$.

PROOF. Since for any $f$ in $\mathrm{L}^{2}$,

$$
\begin{aligned}
\left(C_{T}^{*} C_{T}^{2} f, f\right) & =\left(C_{T}^{2} f, C_{T}^{2} f\right)=\int h_{0}|f|^{2} d m, \\
& =\left(M_{h_{0}} f, f\right),
\end{aligned}
$$

where $M_{h}$ is the multiplication operator induced by $h_{0}$, therefore $C_{T}^{*^{2}} C_{T}^{2}=M_{h}$. Similarly it can be seen that $\mathrm{C}_{\mathrm{T}}^{*} \mathrm{C}_{\mathrm{T}}=\mathrm{M}_{\mathrm{f}} \cdot \mathrm{C}_{\mathrm{T}}$ is M-quasi-hyponormal if and only if

$$
\mathrm{M}^{2} \mathrm{C}_{\mathrm{T}}^{*^{2}} \mathrm{C}_{\mathrm{T}}^{2}-\left(\mathrm{C}_{\mathrm{T}}^{*} \mathrm{C}_{\mathrm{T}}\right)^{2} \geqq 0
$$

This implies that

$$
M^{2} M_{h_{0}}-M_{f_{0}}^{2} \geq 0
$$

that is $\mathrm{f}_{0}^{2} \leqq \mathrm{M}^{2} \mathrm{~h}_{\mathrm{o}}$.

Hence the result.

COROLLARY. Let $\mathrm{C}_{\mathrm{T}} \varepsilon \mathrm{B}\left(\ell^{2}\right)$. Then $\mathrm{C}_{\mathrm{T}}$ is M-quasi-hyponurmal if and only if $f_{0} \leqq M^{2} g_{0}$.

PROOF. Since $h_{0}=f_{0} \cdot g_{0}$ and $f_{0}$ is positive, therefore, by above theorem we get the result.

THEOREM 2.2. Let $C_{T} \varepsilon B\left(l^{2}\right)$. Then $C_{T}$ is M-quasi-hyponormal if and only if $\mathrm{C}_{\mathrm{T}}$ is M-paranormal.

PROOF. Necessity is true for any bounded cperator A. For the sufficiency, let $\mathrm{C}_{\mathrm{T}}$ be $\mathrm{M}$-paranormal, then 


$$
\begin{aligned}
& \left\|\mathrm{C}_{\mathrm{T}} \mathrm{X}_{\{\mathrm{n}\}} \mid\right\|^{2} \leqq \mathrm{M}\left\|_{\mathrm{T}} \mathrm{X}_{\{\mathrm{n}\}}\right\|^{2} \text { for all } \mathrm{n} \varepsilon \mathrm{N} \\
& \text { or } s\left|\mathrm{X}_{\{\mathrm{n}\}} \mathrm{oT}\right|^{2} \mathrm{dm} \leqq M\left(s\left|\mathrm{X}_{\{\mathrm{n}\}} \circ \mathrm{oT}^{2}\right|^{2} \mathrm{dm}\right)^{1 / 2} \\
& \text { or } s\left|\mathrm{X}_{\{\mathrm{n}\}}\right|^{2} \mathrm{dmT}^{-1} \leqq M\left(s\left|\mathrm{X}_{\{\mathrm{n}\}}\right|^{2} \mathrm{dm}(\mathrm{ToT})^{-1}\right)^{1 / 2} \\
& \text { or } \int_{\{n\}} f_{\circ} d m \leqq M\left(\int_{\{n\}} h_{o} d m\right)^{1 / 2} \\
& \text { or } f_{0}^{2}(n) \leqq M^{2} h_{0}(n) \quad \text { for all } n \text { in } N \text {. }
\end{aligned}
$$

Hence $\mathrm{f}_{0}^{2} \leqq \mathrm{M}^{2} \mathrm{~h}_{0} ; \mathrm{C}_{\mathrm{T}}$ is $\mathrm{M}$-quasi-hyponormal.

THEOREM 2.3. Let $\mathrm{C}_{\mathrm{T}} \in \mathrm{B}\left(\ell^{2}\right)$ and $\mathrm{T}: \mathrm{N} \rightarrow \mathrm{N}$ be one-to-one. Then the following are equivalent.
(i) Normal
(ii) M-hyponormal
(iii) M-quasi-hyponormal.

PROOF. (i) implies (1i), (ii) implies (iii) are always true for any bounded operator A. We show that (iii) implies (i). Let $C_{T}$ be M-quasi-hyponormal. Then $\left\|C_{\mathrm{T}}^{*} \mathrm{C}_{\mathrm{T}} \mathrm{f}\right\| \leqq \mathrm{M}\left\|\mathrm{C}_{\mathrm{T}}^{2} \mathrm{f}\right\|$ for all $\mathrm{f}$ in $\ell^{2}$. Now $\mathrm{T}$ is onto because if $\mathrm{T}$ is not onto then $N \mid T(N)$ is non-empty and for $n \varepsilon N \mid T(N)$

$$
\left\|\mathrm{C}_{\mathrm{T}}^{*} \mathrm{C}_{\mathrm{T}} \mathrm{x}_{\{\mathrm{n}\}}\right\|=1 \text { and }\left\|\mathrm{C}_{\mathrm{T}} \mathrm{C}_{\mathrm{T}} \mathrm{x}_{\{\mathrm{n}\}}\right\|=0
$$

There exists no $M>0$ such that $C_{T}$ is $M$-quasi-hyponormal which is a contradiction. Since $\mathrm{T}$ is one-to-one, therefore, $\mathrm{T}$ is invertible, by Theorem $2.2[4] \mathrm{C}_{\mathrm{T}}$ is invertible and $C_{T}$ is normal by Theorem 2.1 [3].

Here we give an example of a composition operator on $\ell^{2}$ which is M-hyponormal but not hyponormal.

EXAMPLE 1. Let $\mathrm{T}: \mathrm{N} \mathrm{N}$ be the mapping such that

$$
\begin{aligned}
& T(1)=2, \quad T(2)=1, \quad T(3)=2 \text { and } \\
& T(3 n+m)=n+2, m=1,2,3 \quad \text { and } n \varepsilon N .
\end{aligned}
$$

Then $C_{T}$ is not hyponormal as $f_{0}$ oT $f_{0}$ for $n=1 . C_{T}$ is $M$-hyponormal for $M \geqq \sqrt{2}$.

EXAMPLE 2. Let $\mathrm{T}: \mathrm{N} \rightarrow \mathrm{N}$ be defined by $\mathrm{T}(1)=2, \mathrm{~T}(2)=1, \mathrm{~T}(3 \mathrm{n}+\mathrm{m})=\mathrm{n}+1$, $\mathrm{m}=0,1,2$ and $\mathrm{n} \varepsilon \mathrm{N}$. Then $\mathrm{C}_{\mathrm{T}}$ is $\sqrt{2}$ - quasi-hyponormal but $\mathrm{C}_{\mathrm{T}}$ is $\operatorname{not} \sqrt{2}$ -hyponormal. $\mathrm{C}_{\mathrm{T}}$ is not quasi-hyponormal also.

\section{REFERENCES}

1. SURI, P.R. and SINGH, N. M-Quasi-Hyponormal Operators, Bul1. Austral. Math. Soc. (Communicated).

2. ARORA, S.S. and KUMAR, R. M-Paranormal Operators, Publications De L'Institut Mathematique Nouvelle Serie 29(1981), 5-13.

3. SINGH, R.K., GUPTA, D.K. and KOMAL, B.S. Some Results On Composition Operators on $\ell^{2}$, Internat. J. Math. and Math. Sci. 2(1979), 29-34.

4. SINGH, R.K. and KOMAL, B.S. Composition Operator on $\ell^{\mathrm{P}}$ and its Adjoint, Proc. Amer. Math. Soc. 70 (1978), 21-25. 


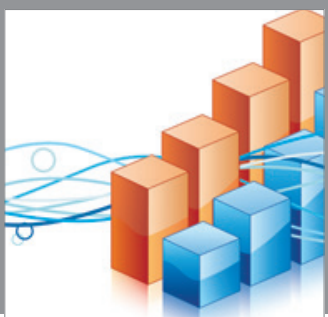

Advances in

Operations Research

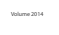

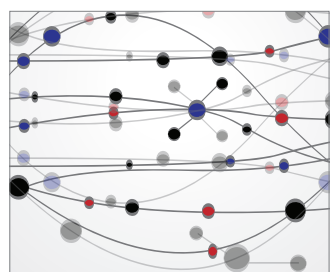

\section{The Scientific} World Journal
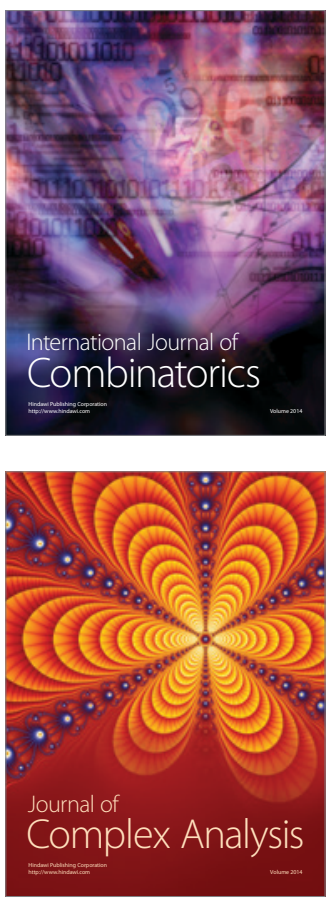

International Journal of

Mathematics and

Mathematical

Sciences
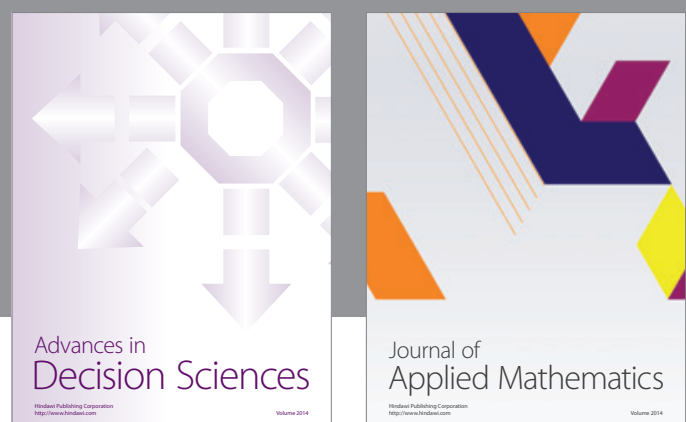

Journal of

Applied Mathematics
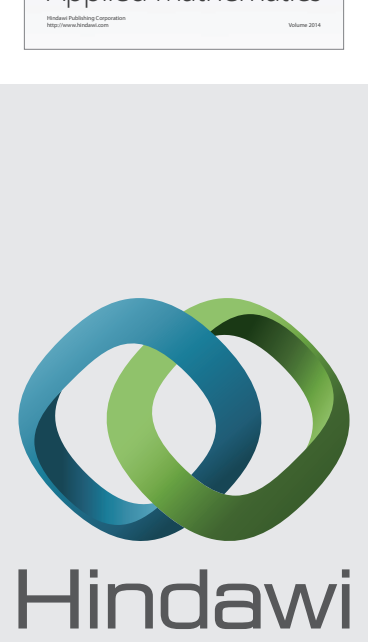

Submit your manuscripts at http://www.hindawi.com
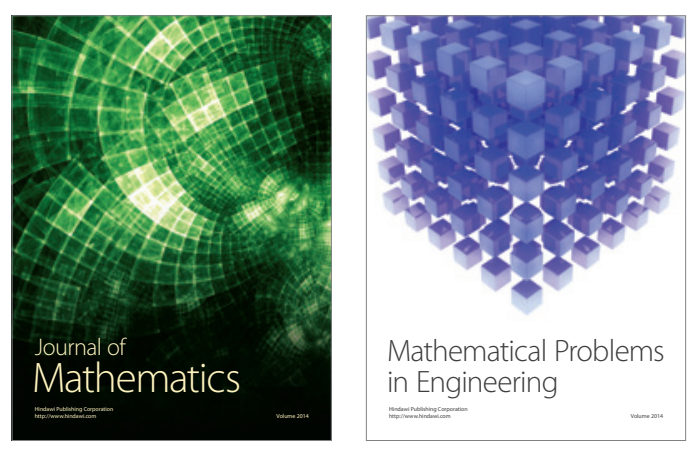

Mathematical Problems in Engineering
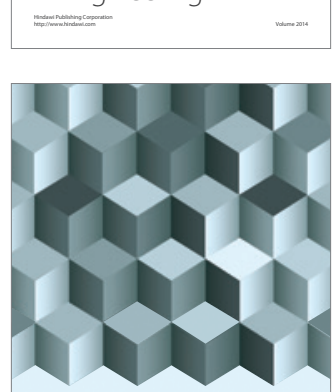

Journal of

Function Spaces
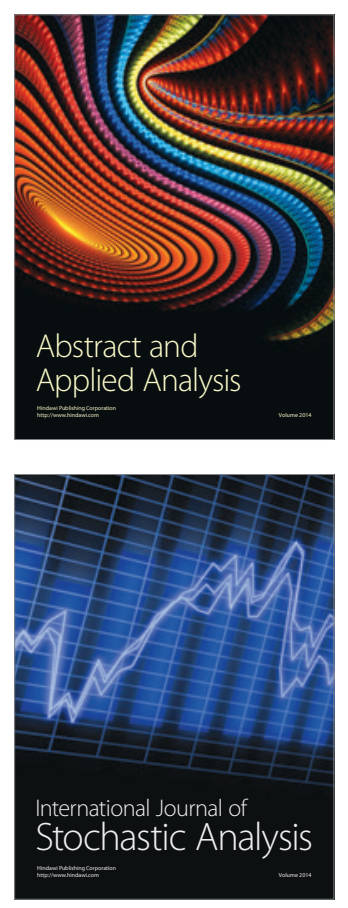

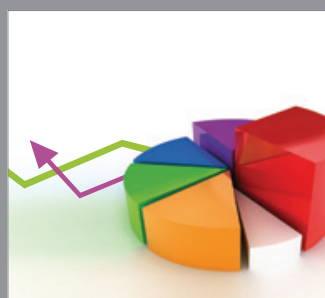

ournal of

Probability and Statistics

Promensencen
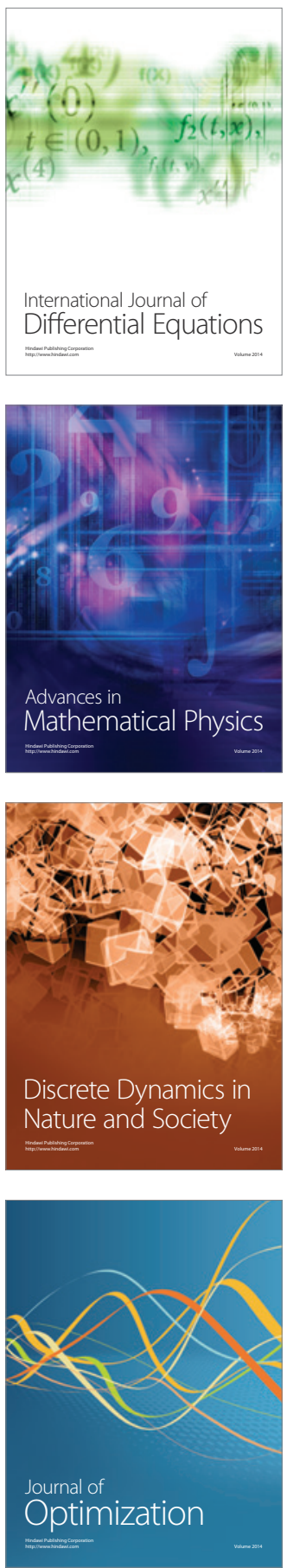